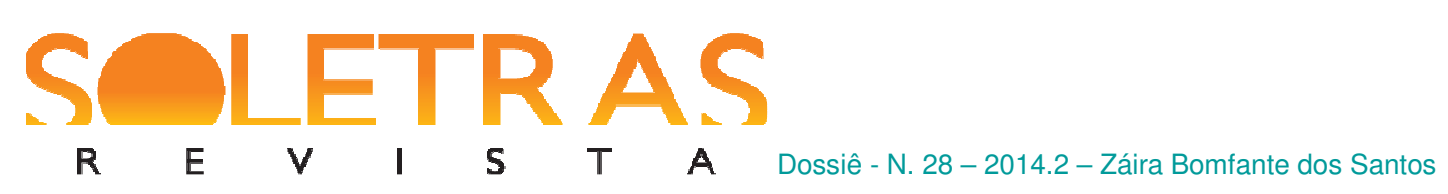

\title{
A Linguística Sistêmico-Funcional: algumas considerações
}

Záira Bomfante dos Santos ${ }^{1}$

Universidade Federal dos Vales do Jequitinhonha e Mucuri

Resumo: Este trabalho tem o propósito de apresentar um breve panorama da Linguística Sistêmico-Funcional baseado nas concepções de Halliday (1994) e Halliday e Matthiessen (2004) por caracterizarem a teoria numa perspectiva social, rompendo com os paradigmas do formalismo linguístico. Halliday e Matthiessen (2004) estudam a linguagem como uma atividade social - parte da sociedade e dos usos da linguagem, uma situação de interativa propondo um enfoque na concentração da atenção nos usuários e nos usos da língua. Assim, os autores propõem a Gramática Sistêmico-Funcional (GSF), situando a língua em seu contexto social, ultrapassando o limite da sentença e avançando para análise de textos. A partir de algumas considerações de conceitos-chave da teoria, buscamos explicitar como se dá o funcionamento da linguagem em contextos comunicativos. Ancorada na abordagem funcionalista, destacamos a noção de gramática, língua e sistema, a linguagem na interação social, a visão estratificada de língua para a realização de significados, bem como a noção de metafunção que assenta os significados realizados pela linguagem via interrelação texto e contexto. O que se busca com essa breve introdução da Linguística Sistêmico-Funcional é mostrar como sua teoria fornece ferramentas úteis para se analisar qualquer instância de interação linguística em um contexto de comunicação, identificando elementos linguísticos e sintáticos que são funcionais para fins específicos nesse uso da língua. Para tanto, situamos exemplos de pesquisas no contexto nacional que têm utilizado esse arcabouço teórico.

Palavras-chave: Língua. Gramática. Funções da linguagem. Texto e contexto. Linguística Sistêmico-Funcional.

\section{Considerações iniciais}

Este trabalho tem o objetivo de trazer algumas noções introdutórias da Linguística Sistêmico-Funcional (doravante LSF) baseadas nas noções postuladas por Halliday (1994) e Halliday e Matthiessen (2004), bem como as suas contribuições na apreciação dos usos da linguagem nos espaço sociais.

Para iniciar essa discussão, trazemos um questionamento proposto por Neves (2004), ao pontuar que caracterizar a corrente funcionalista não é uma tarefa simples, mas assumir essa perspectiva representa romper um paradigma formalista que considerava o estudo da

\footnotetext{
${ }^{1}$ Doutora em Estudos Linguisticos pela UFMG. Professora adjunta da área de Letras e Linguística da UFVJM Universidade Federal dos Vales do Jequitinhonha e Mucuri. Atua nos grupos de pesquisa de Análise do Discurso- NAD - da UFMG e Estudos em Gramática Funcional da UFOP - Universidade Federal de Ouro Preto. E-mail: zaira-santos@ hotmail.com.
} 
R E $\quad$ V $\quad$ I $\quad$ S $\quad$ T $\quad$ A Dossiê- N. 28-2014.2-Záira Bomfante dos Santos

linguagem como um fenômeno isolado do seu uso social, alheio aos processos reais de funcionamento. Os formalistas, segundo Neves (cf. 2005), estudam a língua como objeto descontextualizado, preocupando-se com suas características internas, mas não com as relações entre os constituintes e seus significados. Nessa perspectiva teórica, tem em comum postular a língua como um fenômeno homogêneo. Dentro dessa vertente, têm-se como expressão o estruturalismo americano (com Bloomfield, Trager, Bloch, Fries etc.) e de forma menos rigorosa o modelo gerativista proposto por Chomsky.

O funcionalismo está estritamente ligado aos propósitos da Escola Linguística de Praga em que concebiam a linguagem articulada como um sistema de comunicação, centrada com seus usos e funções. A visão funcional da Escola de Praga está na definição de língua, vista como um sistema de meios apropriados a um fim.

Numa concepção geral, a perspectiva funcional tem como premissa básica de interesse a verificação como os usuários da língua se comunicam eficientemente em diversos contextos. Assim, os pontos principais que sedimentam as discussões dentro da perspectiva funcionalista na gramática proposta por Halliday e Matthiessen (2004) são: o uso (em relação ao sistema); o significado (em relação à forma) e o social (em relação ao indivíduo). Considerando a noção funcional da linguagem os autores destacam:

[...] A análise sistêmica revela que a funcionalidade está intrínseca na linguagem: ou seja, toda arquitetura da linguagem está organizada em linhas funcionais. A linguagem se configura a partir das funções que desempenha e tem evoluído na espécie humana. ${ }^{2}$

Nesse propósito, nas seções subsequentes, centramos breves comentários em torno da LSF, propondo delinear uma discussão em torno da noção de gramática, língua, sistema, texto e contexto, bem como a multiplicidade funcional que se constrói na estrutura da língua e forma a base de sua organização lexical e gramatical.

\section{A Linguística Sistêmico-Funcional}

A Linguística Sistêmico-Funcional, teoria linguística originada pelo linguista britânico Michael Alexander Kirkwood Halliday e desenvolvida por seus colegas (cf. HALLIDAY; HASAN, 1989; EGGINS, 1994; THOMPSON, 2003; MARTIN; ROSE, 2003; MARTIN;

\footnotetext{
${ }^{2}$ Nossa tradução de: ...the systemic analysis shows that functionality is intrinsic to language: this is to say, the entire architecture of language is arranged along functional lines. Language is as it is because of the functions in which it has evolved in the human species. (HALLIDAY; MATTHIESSEN, 2004, p. 31).
} 


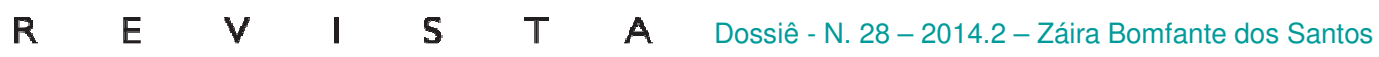

WHITE, 2005), é uma abordagem ao estudo da linguagem que está centrada na noção de "função"; isso porque considera a gramática em termos de como ela é usada para produzir significados. Essa proposta, iniciada nos estudos de Halliday nas décadas de 1960 e 1970, é sistêmico-funcional porque concebe a língua como uma rede de sistemas interligados que o falante faz uso (base funcional) para produzir significados (base semântica) em situações de comunicação. Nessa perspectiva, a língua deixa de ser um mero sistema regulado por regras e passa a ser estudada de um ponto de vista sócio-semiótico, considerando-a como um sistema de produção de significados.

As características da abordagem sistêmico-funcional são assim definidas por Eggins (1994, p.3): o uso da língua é funcional; a função da linguagem é produzir significados; esses significados são influenciados pelo contexto social e cultural em que são negociados; o uso da língua produz significados através de escolhas. Assim, além de ser funcional para a produção de significados, a linguagem é também um sistema semiótico, ou seja, um sistema de codificação convencionalizado, organizado como um conjunto de escolhas. O que faz com que sistemas semióticos diferenciem-se de outros tipos de sistema é que cada escolha adquire um significado em detrimento a outras escolhas que poderiam ter sido feitas. Logo, uma escolha feita revela, dependendo do contexto de comunicação, toda uma rede particular de outras escolhas disponíveis no sistema. Assim, aquilo que interessa ao linguista sistêmico é analisar quais escolhas linguísticas foram feitas em um determinado contexto de comunicação e como essas escolhas produzem significados.

Nesses parâmetros, a gramática é funcional no sentido de que busca dar conta de como a linguagem é usada. Halliday (1985) pontua que tudo que é dito ou escrito aparece em algum contexto de uso. São os usos da língua que dão forma ao sistema que, por milhares de gerações, deram forma ao sistema; que a linguagem se desenvolveu para satisfazer a necessidades humanas, e o modo que ela organizada é funcional com respeito a essas necessidades, ou seja, não é arbitrário. Uma gramática funcional é essencialmente uma gramática 'natural' no sentido de que tudo nela pode ser explicado, pois, por referência a como a linguagem é usada.

Ao propor explicar a organização da língua somente a partir do uso, a LSF entende o sistema linguístico como um leque de possibilidades aberto aos falantes. É nesse sentido que a escolha feita pelo falante interessa de perto ao linguista sistêmico, visto que suas escolhas nos sistemas da língua não são aleatórias, mas sim e carregadas de valores sociais. 
$\begin{array}{llllllll}\mathbf{R} & \text { E } & \mathbf{V} & \mathbf{I} & \mathbf{S} & \mathbf{T} & \mathbf{A} & \text { Dossiê - N. 28-2014.2-Záira Bomfante dos Santos }\end{array}$

\section{As noções de Gramática, Língua e Sistema}

Ao propor os princípios da LSF, Halliday $(1978 ; 1994)$ entende a gramática de uma língua como um conjunto altamente complexo de sistemas de opções que o falante faz uso ao estruturar suas enunciações e que o ouvinte usa para interpretar enunciações. Por isso, é considerada a unidade central de processamento da linguagem, a base onde significados são criados. Essa visão do que é a gramática de uma língua implica dizer que toda gramática, isto é, todos os sistemas de significado em potencial, evolui a partir das necessidades dos falantes de uma dada sociedade.

Dois conceitos essenciais para a compreensão da linguagem na perspectiva da LSF são os de sistema e função. Halliday e Matthiessen (2004) entendem a língua enquanto organizada em dois eixos: o sintagmático (o nível da estrutura) e o paradigmático (o nível das escolhas). O primeiro apreende as relações pelas quais os signos ajustam-se em sequências ou estruturas. Os autores explicam que a estrutura é a ordenação sintagmática na língua: "o que vai junto com o que". Esse eixo é concebido como uma cadeia que estrutura a oração (os elementos linguísticos são ordenados linearmente). O segundo eixo captura as relações de oposição ou escolha entre os signos nos sistemas da língua. É neste eixo que Halliday desenvolve a teoria da LSF, já que a língua é um recurso para a produção de significados em contextos particulares, e não de sequências de elementos ordenados linearmente (cf. EGGINS, 1994). Ou como pontuam Halliday e Matthiessen (2004, p.23), "uma língua é um recurso para a produção de significado, e significado reside nos padrões sistêmicos de escolha”. Por isso, a abordagem sistêmica dá prioridade teórica às relações de escolhas feitas nos sistemas da língua.

As escolhas no eixo paradigmático são capturadas através de sistemas. O resultado dessas escolhas são estruturas construídas através de enunciações realizadas. Em outras palavras, os textos que produzimos consistem, essencialmente, nas escolhas e na organização de significados feitas nos dois eixos, o paradigmático e o sintagmático. Logo, percebe-se que Halliday coloca o eixo sintagmático como o nível da realização, isto é, o nível em que se encontram as unidades realizadas (as escolhas feitas nos sistemas).

Dentro dessas considerações temos o seguinte paradigma funcional em relação à língua: 


\section{SOLETR AS}

$\begin{array}{lllllll}\text { R } & \text { E } & \text { V } & \text { I } & \text { S } & \text { T } & \text { A Dossiê - N. 28-2014.2-Záira Bomfante dos Santos }\end{array}$

\begin{tabular}{|c|c|}
\hline Como definir a Língua & Instrumento de interação social \\
\hline Principal função da Língua & Comunicação \\
\hline O sistema e seu uso & O estudo do sistema deve fazer-se dentro do quadro do uso \\
\hline Língua e contexto/situação & $\begin{array}{c}\text { A descrição das expressões deve fornecer dados para a } \\
\text { descrição de seu funcionamento num dado contexto }\end{array}$ \\
\hline Aquisição da Linguagem & $\begin{array}{c}\text { Faz-se com ajuda de input extenso e estruturado de dados } \\
\text { apresentados no contexto natural }\end{array}$ \\
\hline
\end{tabular}

Quadro 1. Paradigma funcional da linguagem (baseado em NEVES, 2005, p. 47)

A noção de teoria "sistêmica" consiste, então, justamente no fato de uma teoria de significados enquanto escolhas. A gramática de uma língua é uma rede de escolhas significativas interrelacionadas e que estão à disposição do falante, que dependendo do contexto situacional e cultural faz escolhas particulares nos sistemas da língua. Na perspectiva hallidayana, portanto, a língua não é vista como um sistema de regras que representa nossos pensamentos, mas sim como um sistema de produção de significados através de escolhas. Isso confere a ela um caráter interativo e dinâmico, visto que os significados são construídos e reconstruídos a cada vez que o sistema é acessado, isto é, a cada vez que usamos a língua na produção dos textos em um dado contexto.

\section{Da noção de texto e contexto}

De acordo com a Gramática Sistêmico-Funcional (GSF), o texto é entendido como um fenômeno social e, como tal, é condicionado por outros sistemas sociais. A língua é um sistema onde o indivíduo faz suas escolhas segundo o contexto social em que está inserido e a gramática tem como função auxiliar na análise dos textos. Nesses termos, a linguagem é tida como "um sistema de significados" que possui uma cadeia de sistemas que possibilita que tais significados sejam realizados. Na abordagem hallidayana, a linguagem se organiza não só em torno do seu sistema linguístico, mas também em torno do seu sistema de dados do contexto social. Esses dois sistemas se interrelacionam numa rede sistêmica. Segundo Meurer,

Um dos princípios centrais da Linguística Sistêmico-Funcional (LSF) estabelece que todas as possíveis redes semânticas devem se relacionar a especificações contextuais "acima" dessas redes em termos de "categorias de alguma teoria social geral ou uma teoria de comportamento", e "abaixo", em termos de "categorias de formas linguísticas do extrato da gramática". (MEURER, 2004, p.133-134). 


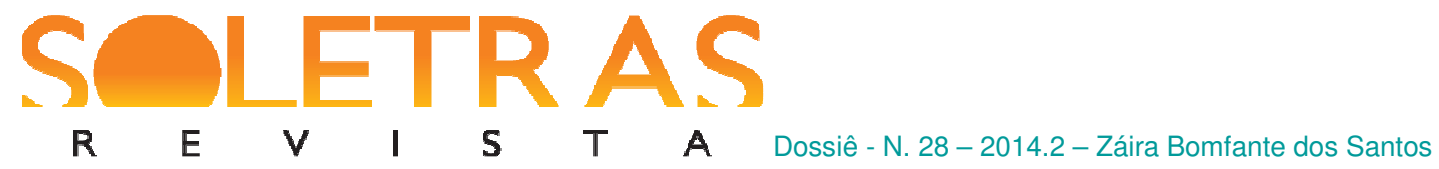

De acordo com o autor, nas análises de textos com base na LSF, todos os significados têm uma conexão direta com o contexto social - acima - e uma conexão direta com os elementos léxico-gramaticais - abaixo, visto que os textos carregam influências do contexto em que foram produzidos. Portanto, na LSF, não se analisa um texto unicamente em termos dos elementos léxico-gramaticais. Ao contrário, cada significado deve ser relacionado simultaneamente a rotinas sociais e formas linguísticas. Neste viés, segundo Eggins e Martin (1997, p.234), "teorizar a relação entre linguagem e contexto, e como ele entra no texto é a preocupação central dos teóricos de registro".

$\mathrm{Na}$ perspectiva funcional, as estruturas da língua evoluem como um resultado das funções de produção de significados a que servem dentro dos sistemas sociais ou culturais em que são usadas. (HEBERLE, 2000, p.297). Desta forma, a definição de texto como um evento de produção de significado não pode ser dissociado da influencia do contexto social:

Nós podemos definir texto, talvez da forma mais simples, dizendo que ele é a língua que é funcional. Por funcional, queremos dizer simplesmente que a língua está sendo usada em algum contexto, em oposição a palavras ou sentenças isoladas que poderiam ser colocadas em um quadro (...). Assim, qualquer instância de língua viva inserida em um contexto de situação, podemos denominar texto. Ele pode ser escrito ou falado, ou de fato em qualquer outro meio de expressão que nos leva a refletir ${ }^{3}$. (HALLIDAY, 1989, p. 10).

Para o autor, a relação entre texto e contexto é teorizada como probabilística e não determinista: um interactante para alcançar uma meta cultural particular é provável iniciar um texto a partir de um gênero particular, e este texto é provável se desdobrar em uma forma particular - mas o potencial para as alternativas está inerente na relação dialógica entre linguagem e contexto. Logo, a relação entre um texto e suas condições de produção passa necessariamente pelo contexto em que é produzido e no qual será negociado. Isso significa dizer que há uma relação dialética, interna e dinâmica entre texto e contexto. As escolhas linguísticas constroem o contexto social em que o texto é negociado, ao mesmo tempo em que são determinadas por esse mesmo contexto. Portanto, um não opera sem o outro. A figura a seguir sumariza essa discussão.

\footnotetext{
3 Nossa tradução de: We can define text, in the simplest way perhaps, by saying that it is language that is functional. By functional, we simply mean language that is doing some job in some context, as opposed to isolated words or sentences that I might put up on the blackboard [...]. So any instance of living language that is playing some part in a context of situation, we shall call a text. It may be either spoken or written, or indeed in any other medium of expression that we like to think of.
} 


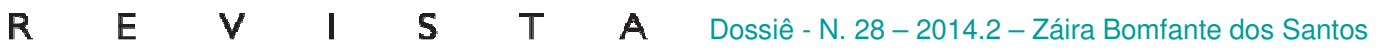

Figura 1. Complexo Sistêmico Funcional de Halliday

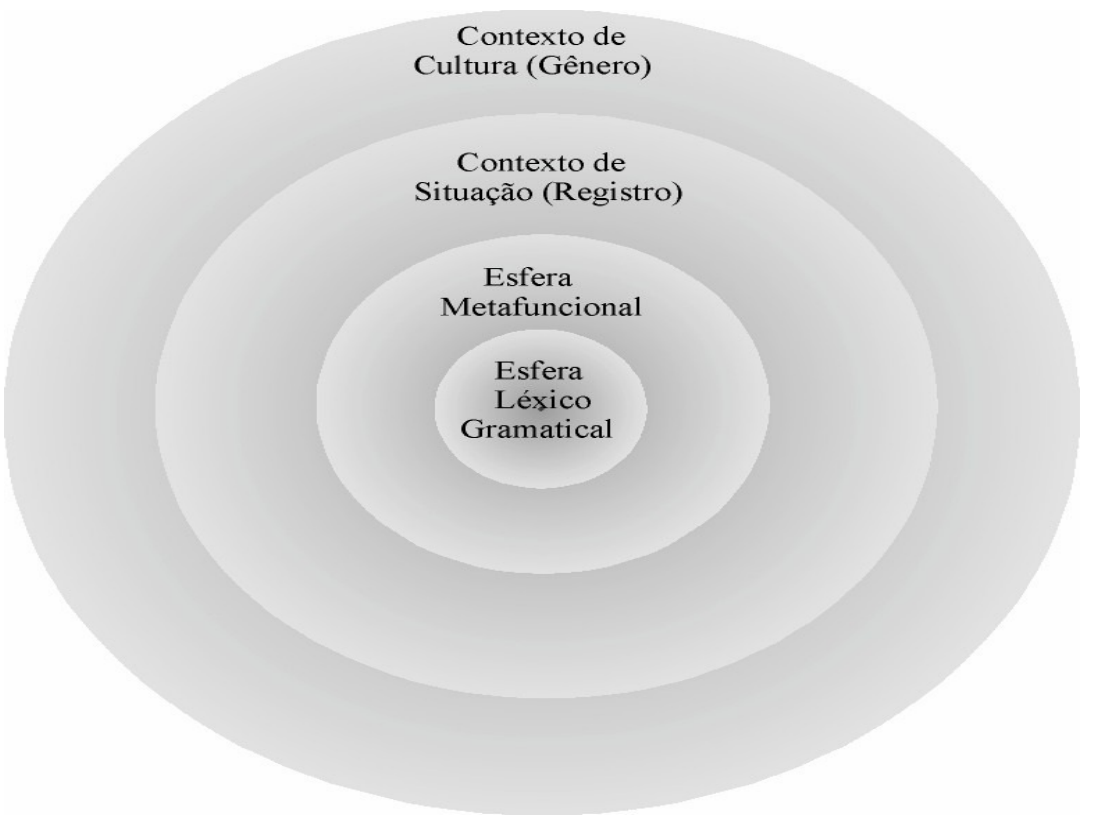

Halliday $(1985,2004)$ estabeleceu um ponto importante ao relacionar um modelo de linguagem que pode ser naturalmente relacionado à organização do contexto com significados ideacionais - fontes para construção de conteúdo- usados para construir o campo (a ação social); significados interpessoais - fontes para interação - usados para negociar as relações (o papel da estrutura); significados textuais - fontes para organização textual - usados para desenvolver o modo (a organização simbólica).

\begin{tabular}{|c|c|c|}
\hline $\begin{array}{c}\text { Variáveis de } \\
\text { registro }\end{array}$ & $\begin{array}{c}\text { Metafunções da } \\
\text { linguagem }\end{array}$ & Realização léxico-gramatical \\
\hline Campo & Ideacional & $\begin{array}{c}\text { Transitividade e relações lógico- } \\
\text { semânticas }\end{array}$ \\
\hline Relação & Interpessoal & Modo, modalidade, atitude \\
\hline Modo & Textual & Tema e Rema \\
\hline
\end{tabular}

Quadro 2: Relação entre contexto e metafunções da linguagem

Essas três variáveis são denominadas variáveis de registro, e permitem marcar o contexto situacional nos textos. Segundo Eggins e Martin (1997, p.243), outra camada de contexto é necessária, além do situacional, o contexto cultural - onde os são gêneros gerados - se colocando acima e além do campo, modo e relações. A análise nesse nível concentra-se em explicitar quais combinações de variáveis de campo, relações e modo uma cultura possibilita, e como estes são planejados em etapas e orientados em um processo social. Para 
$\begin{array}{llllllll}\text { R } & \text { E } & \text { V } & \text { I } & \text { S } & \text { T } & \text { A } & \text { Dossiê - N. 28-2014.2-Záira Bomfante dos Santos }\end{array}$

Eggins e Martin (1997, p.251), os termos registro (contexto de situação) e gênero (contexto de cultura) identificam as duas maiores camadas de contextos que têm um impacto nos textos, e são, portanto, as duas principais dimensões de variação entre os textos.

Na perspectiva hallidayana

[...] não há nenhuma faceta da experiência humana que não possa ser transformada em significado. Em outras palavras, a linguagem fornece uma teoria da experiência humana, e certos recursos lexicogramaticais de cada língua são dedicados a esta função ${ }^{4}$ (HALLIDAY, 2004, p. 29).

Por entender que a linguagem se organiza em torno de um propósito - uma função - ele estabelece para os componentes funcionais da língua três metafunções: metafunção ideacional, interpessoal e textual, as quais, segundo o linguista, dão conta dos modos de usos da linguagem.

\section{As metafunções da linguagem}

A LSF entende que a linguagem se desenvolveu com o propósito fundamental de satisfazer as necessidades de comunicação humana, isto é, de possibilitar ao homem a produção e troca de significados, isso porque não interagimos de modo a trocar sons, palavras ou sentenças. É nesse sentido que Halliday (1978) propõe a multifuncionalidade de todo uso da língua. Em nossas práticas comunicativas, a linguagem desempenha simultaneamente três metafunções básicas, quais sejam: a produção de significados ideacionais, interpessoais e textuais. $\mathrm{O}$ autor ainda pontua que essas metafunções não atuam de forma isolada, mas interagem na construção do texto conferindo-lhes um caráter multifuncional. Além disso, essas metafunções se refletem na estrutura da oração e se relacionam diretamente com a léxico-gramática de uma língua.

Os significados ideacionais são significados sobre como representamos nossa experiência na linguagem, visto que estamos sempre falando sobre alguma coisa ou alguém fazendo alguma coisa. Os significados interpessoais correspondem às relações sociais estabelecidas entre os interactantes e às atitudes expressas por eles na linguagem, já que estamos sempre expressando atitudes e desempenhando papeis ao usar a língua. E os

\footnotetext{
${ }^{4}$ Nossa tradução de [...] there is no facet of human experience which cannot be transformed into meaning. In other words, language provides a theory of human experience, and certain of the resources of the lexicogrammar of every language are dedicated to that function (HALLIDAY, 2004, p. 29).
} 
$\begin{array}{llllllll}\text { R } & \text { E } & \text { V } & \text { I } & \text { S } & \text { T } & \text { A } & \text { Dossiê - N. 28-2014.2-Záira Bomfante dos Santos }\end{array}$

significados textuais servem para organizarmos nossa informação enquanto mensagem, visto que estamos sempre estruturando nosso dizer em forma de textos coerentes.

\begin{tabular}{|l|l|l|}
\hline Metafunção & \multicolumn{1}{|c|}{ Significado } & Status correspondente na oração \\
\hline Ideacional & Representar o mundo da experiência & Oração como representação \\
\hline Interpessoal & Desempenhar relações sociais & Oração como troca \\
\hline Textual & Criar relevância para o contexto & Oração como mensagem \\
\hline
\end{tabular}

Quadro 3: As metafunções e seus desdobramentos (HALIDAY, 1994, p. 36)

As metafunções realizam-se a partir das necessidades da situação, das características do contexto de situação. Segundo Barbara e Macêdo (2009), o homem, situado histórica e socialmente numa cultura, seleciona o modo como vai produzir texto e a forma como interagirá com os participantes da interação, considerando um conhecimento, um conteúdo experiencial que será realizado como seleção que fará. Assim, textos terão características diferentes, dependendo dos participantes e da finalidade a que sirvam.

Os modos de significado explicitados no quadro 3 são componentes funcionais do sistema semântico da língua que são produzidos em qualquer interação social, funcionando simultaneamente na construção do texto. Por isso, eles não se excluem, mas se interrelacionam. Cada um dos três significados é resultado de um sistema oracional específico. O que permite à língua produzir essa multifuncionalidade semântica é um nível intermediário de codificação chamado de léxico-gramática.

Assim, conforme ressaltam Halliday e Matthiessen (2004), a linguagem é entendida sob dois propósitos: a representação do mundo (dar sentido a nossa experiência) e a interação com os outros (influir sobre os outros), sendo esses propósitos organizados em forma de informação, mensagem (texto). Logo, são as configurações de significados e as relações entre esses significados que conferem à língua uma unidade coerente e significativa. Nessa perspectiva, Neves (1997) escreve que

[...] uma gramática funcional é aquela que constrói todas as unidades de uma língua - suas orações, suas expressões - como configurações orgânicas de funções, e, assim, tem cada parte interpretada como funcional em relação ao todo" (NEVES, 1997, p. 63).

Por conseguinte, podemos depreender que a LSF está voltada para o funcionamento de significados realizados em textos. 


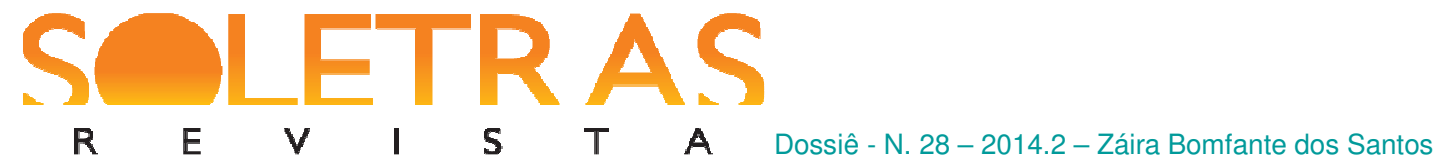

\subsection{A metafunção ideacional}

Em uma perspectiva sistêmico-funcional da linguagem, a realização do significado ocorre dentro da oração. Consequentemente, tal perspectiva oferece uma gramática da oração que, dentro da dimensão ideacional do significado, compreende a "oração como representação", a linguagem sendo usada para descrever a experiência humana, uma corrente de eventos ou acontecimentos. A metafunção ideacional é distinguida em dois componentes, o experiencial - relacionado com as opções dentro de um sistema de transitividade - e o lógico - relacionado com as inter-relações das orações que estão amparadas pelos processos (HALLIDAY; MATHIESSEN, 2004).

$\mathrm{Na}$ perspectiva experiencial, manifestamos nosso conhecimento de mundo no texto, o conhecimento das ideias. Assim, a metafunção ideacional da léxico-gramática organiza as ideias do indivíduo e as representam. As representações dos significados ideacionais estão sempre envolvidas com os construtos sociais e culturais (KRESS; VAN LEEUWEN, 2002) e são realizadas por um sistema gramatical.

Neste viés, a linguagem reflete nossa visão de mundo como um construto de acontecimentos (Processos) que envolvem entidades (Participantes) com um pano de fundo de detalhes de tempo, lugar, modo etc. (Circunstâncias). Assim, os grupos verbais, nominais e preposicionais são os constituintes das orações respectivamente aos Processos, Participantes e Circunstâncias.

Halliday e Matthiessen (2004, p. 172) propõem o sistema de transitividade da língua para ordenar e representar nossas experiências. Ele apresenta uma condição de entrada chamada de experiencial, permitindo, para a representação de um fragmento da experiência, a escolha de um dos seis processos disponíveis (verbal, mental, comportamental, material, existencial ou relacional). Para os linguistas, a dimensão ideacional do significado permite ao leitor levantar questões sobre quem está agindo, que tipos de ações estão sendo empreendidas e quem ou o que está de acordo. A figura seguinte sintetiza essas informações:

Figura 2. Os tipos de processos (Halliday e Matthiessen, 2004) 


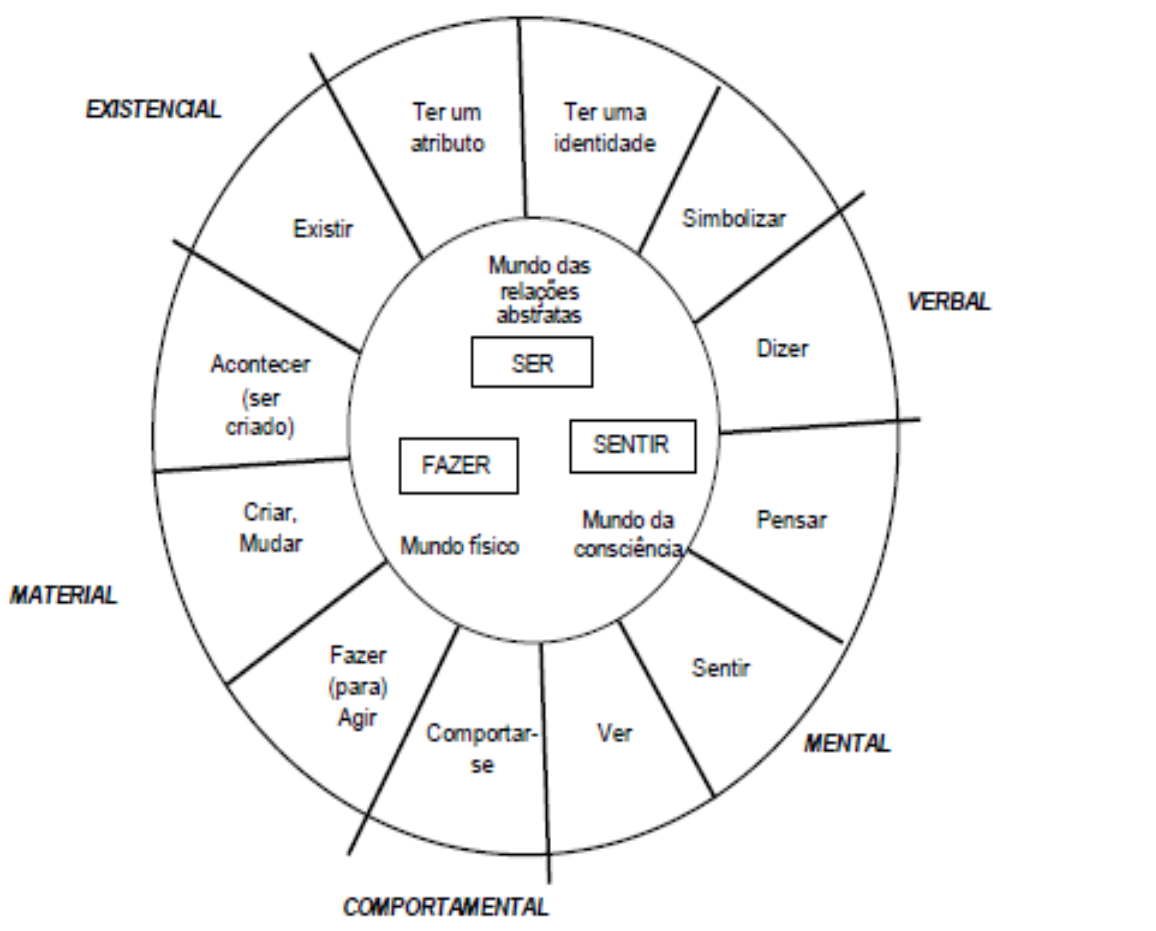

Como exemplo de pesquisa da metafunção ideacional, dentro do componente experiencial, trago parte da pesquisa de Brent (2011) em que analisa as escolhas sistêmicas de transitividade na representação de escândalos políticos. Brent analisa mais precisamente como o discurso jornalístico da revista VEJA faz a representação de escândalos políticos do mensalão. O pesquisador encontra em seus dados a recorrência de todos os processos na representação dos participantes. Trago as recorrências dos processos materiais para representar a agentividade dos participantes na construção do evento:

(1) O PT [Ator] assombra [Processo Material] o Planalto [Meta].

(2) (...) um ministro viria a público dizer que o PT [Ator] estava pagando [Processo Material] o preço [Escopo] por andar com "más companhias" [Circunstância de razão].

(3) A revista noticiara que o PT [Ator] comprara [Processo Material] o apoio do PTB [Meta] por 10 milhões de reais [Circunstância de meio], mas entregara [Processo Material] só parte do dinheiro [Escopo].

No exemplo (1), temos o título da primeira reportagem publicada por VEJA após as denúncias de Roberto Jefferson sobre a existência do mensalão. Nesse recorte, o PT atua como ator da ação de assombrar o Palácio do Planalto. Ao apresentar essa construção experiencial, o jornalista sinaliza ao leitor aspectos significativos para o modo como o texto 
$\begin{array}{llllllll}\text { R } & \text { E } & \text { V } & \text { I } & \text { S } & \text { T } & \text { A } & \text { Dossiê - N. 28-2014.2-Záira Bomfante dos Santos }\end{array}$

deve ser apreendido. Considerando que os títulos fazem uma leitura global do texto, informando o que há de mais proeminente no discurso da notícia. Nota-se no título acima que o PT será posto como uma das principais entidades a praticar e participar das ações e situações descritas no texto, pois é nesse sentido que ele é tematizado e posto em primeiro plano na oração.

Em todos os exemplos o PT é posto em primeiro plano, onde sua agentividade é marcada de forma explícita. Isso revela traços particulares na constituição da representação do escândalo, mostrando que as escolhas linguísticas concedem ao jornalista (à revista) a realização de seu propósito ideológico, o que confere ao discurso jornalístico um de seus princípios mais relevantes: o poder de dar visibilidade a eventos, situações e pessoas.

\subsection{A metafunção interpessoal}

A metafunção interpessoal está relacionada com o aspecto da organização da mensagem como um evento interativo que envolve falante, escritor e público. Centra-se nas relações de troca da oração. Ela permite ao falante participar do evento da fala fazendo com que ele crie e mantenha relações sociais. É através desta função que os falantes expressam suas opiniões, julgamentos e atitudes. Esta metafunção é interacional e pessoal, constituindo um componente da linguagem que serve para organizar e expressar tanto o mundo interno como o mundo externo do indivíduo.

No processo interação lançamos mão de diferentes papéis de fala. Os papéis de fala mais fundamentais são: dar e demandar, em ambos o falante dá alguma coisa ao ouvinte (informação) ou requer algo. De acordo com Halliday e Matthiessen (2004, p. 107), "essas categorias envolvem noções complexas em que "dar" significa convidar a receber e demandar convidar a dar. O falante não só faz algo pra si como também requer algo do ouvinte”. Outra distinção básica entre dar e demandar se relaciona com a natureza do que está sendo trocado: bens \& serviços ou informação. Essas duas variáveis definem as quatro funções discursivas primárias: oferta, comando, declaração e pergunta como sintetiza o quadro a seguir:

Quadro 4. Papéis de fala e mercadorias na interação

\begin{tabular}{ccc}
\hline PAPEL DE FALA & INOFRMAÇÃO & BENS E SERVIÇOS \\
\hline DAR & declaração & oferta \\
\hline DEMANDAR & pergunta & comando \\
\hline
\end{tabular}




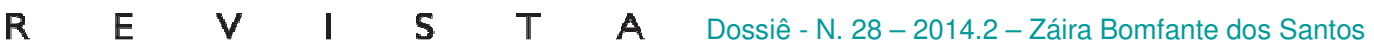

Segundo Halliday, quando a linguagem é usada para trocar informações, a oração toma forma de proposição, possui função semântica de proposição, algo que pode ser argumentado, afirmado, negado, questionado, aceito etc. Contudo, o termo proposição não pode se referir a todas as funções da oração num evento interativo, pois excluiria troca de bens e serviços visto que não podem ser afirmados, negados, cabendo ao leitor escolhas relativamente limitadas, assim, possuem uma função semântica de proposta. A metafunção interpessoal é organizada em dois blocos: Modo Oracional é o componente que carrega o argumento da oração e consiste em duas partes: sujeito (o grupo nominal), operador finito (grupo verbal); e o Resíduo - constituído pelos elementos funcionais: predicador, complemento e adjuntos. De acordo com Halliday, é na estrutura do Modo Oracional que recai o peso maior da oração, uma vez que o sujeito é a entidade em que recai a validade da oração, é o responsável pelo funcionamento da oração em um evento interativo; e através do operador finito torna-se possível argumentar a validade da oração em termos de polaridade/ modalidade e tempo.

A pesquisa desenvolvida por Böhkle (2008) mostra que mensagens relacionadas ao gênero social que produzem inseguranças no corpo feminino são estrategicamente exploradas por comerciais com o objetivo de sustentarem diversos ramos da indústria de modificação do corpo incluindo o setor farmacêutico. A investigação analisa uma propaganda de TV promovendo o medicamento Xenical, utilizado para controle de peso, tendo em vista os aspectos multimodais da representação dinâmica dos recursos que compõem o significado do texto como um todo.

$\mathrm{Na}$ análise, considerando o conceito tri-funcional proposto por Halliday \& Mathiessen, em relação aos significados interativos no plano verbal, a pesquisadora observou no registro a ocorrência de papéis de falas de oferta e demanda em várias fases da propaganda numa estratégia de engajamento com o leitor:

\begin{tabular}{|l|l|l|l|}
\hline O que & Eu & faria & com alguns quilinhos a menos? \\
\hline & & passado & Adjunto \\
\hline complemento & Sujeito & predicador & \\
\hline resíduo & Modo oracional interrogativo & Resíduo \\
\hline
\end{tabular}

O modo interrogativo, expressado pela ordem Sujeito + Finito estimula o telespectador a compartilhar a questão de uma forma menos invasiva em que o "eu" aparece como parte 


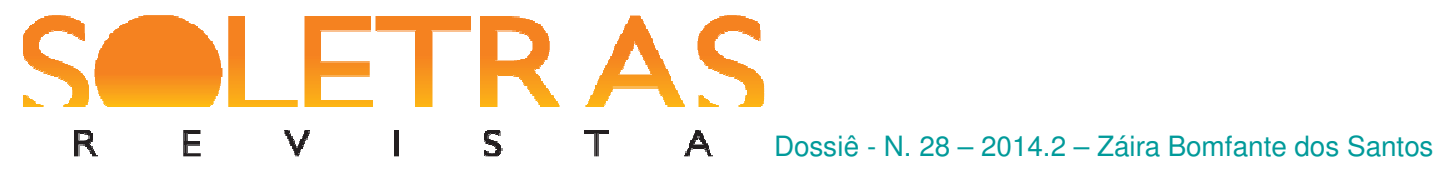

equivalente do "você". Em concordância de transitividade a pergunta leva o telespectador inferir a resposta da participante da propaganda através de um modo declarativo:

\begin{tabular}{|l|l|l|}
\hline Eu & Usaria & saia, fendas, decotes \\
\hline & Passado & \\
\hline sujeito & Predicador & Complemento \\
\hline Modo oracional declarativo & Resíduo & \\
\hline
\end{tabular}

\begin{tabular}{|l|l|l|l|}
\hline Eu & Faria & as pazes & com o espelho \\
\hline & Passado & & \\
\hline sujeito oracional & Predicador & Resíduo & Adjunto \\
\hline $\begin{array}{l}\text { Modo } \\
\text { declarativo }\end{array}$ & & \\
\hline
\end{tabular}

A análise tri-funcional desse tipo de texto (propaganda de TV) indica como os recursos visuais e verbais são astutamente combinados para promover uma interação próxima do telespectador e para produzir mensagens em relação a gênero social as quais reforçam assimetrias de gênero através da fragmentação do corpo feminino.

Trago aqui apenas uma pequena amostra do que tem se observado no que se refere às relações entre os participantes em situações comunicativas. Situo que muitas pesquisas têm sido feitas no campo da interpessoalidade observando, por exemplo, o engajamento dos participantes, as emoções, os julgamentos nas interações a partir da proposta da avaliatividade desenvolvida por (Martin \& White, 2005, Eggins \& Slade, 1997, Vian Jr., Natividade, 2012).

\subsection{A Metafunção textual}

A metafunção textual se ocupa do uso da linguagem na organização do texto sua tessitura. Ela está relacionada ao significado textual que é realizado por decisões que o falante toma com relação à distribuição da informação. Halliday classifica as metafunções como estudo da lingua(gem) no nível das orações. Assim, a oração, concebida como uma unidade na qual os significados de diferentes tipos são combinados, é organizada em torno da estrutura Tema / Rema e Dado /Novo.

O elemento tema serve como ponto de partida da mensagem que orienta e situa a oração dentro do contexto. Assim, sendo o primeiro constituinte da oração, todo o restante da oração denomina-se rema. Quanto à informação semântica contida no texto, distribui-se pelo menos em dois grandes blocos: dado e novo, cuja disposição interfere na construção do sentido. A 


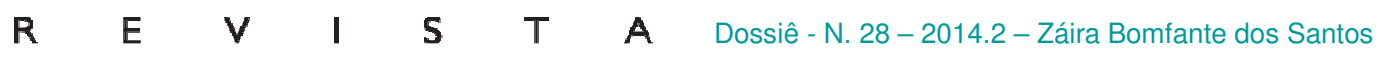

informação dada - aquela que se encontra na consciência dos interlocutores e pode ser recuperada pelo contexto - estabelece pontos de ancoragem para aporte da informação nova.

Como exemplo de trabalho relacionado, contextualizo a pesquisa de Santos (2009) em que investigou como se dá a articulação dos aspectos semióticos e léxico-gramaticais em publicidades femininas brasileiras. Na análise dos dados, nota-se que os produtos anunciados são o ponto de partida (tema) dos anúncios e ocupam a informação dada. Os atributos que qualificam e destacam os resultados desses produtos são organizados textualmente como a informação nova:

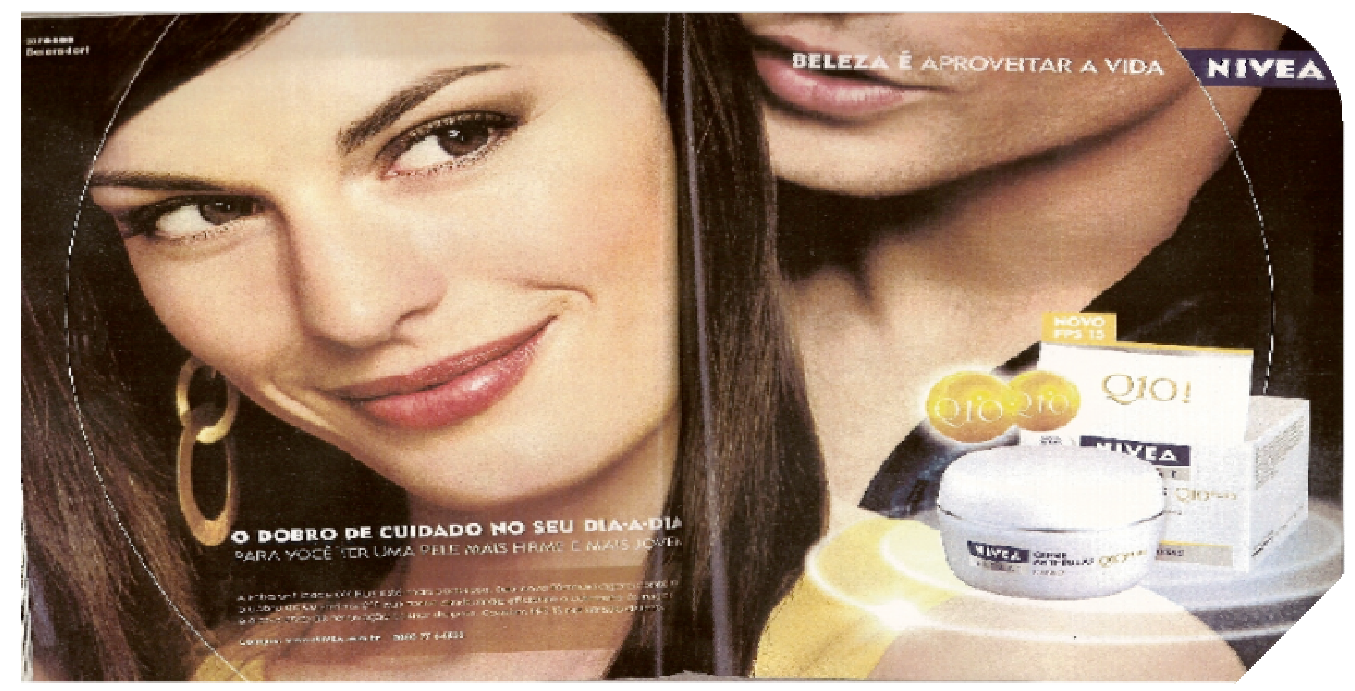

Fonte: Revista Nova

“A linha antiidade Q10 plus (tema) está mais poderosa (rema). Sua nova fórmula agora contém o dobro da coenzina Q10 (tema) que torna ainda mais eficiente o combate às rugas o processo de renovação celular da pele (rema)"

Nota-se na organização do texto verbal uma preocupação de colocar o sujeito 'a linha antiidade' e sua 'nova fórmula' ocupando a posição temática evidenciando o elemento principal dentro do anúncio - o item a ser comercializado.

Com esse trabalho, a autora visou suscitar reflexões sobre como o texto se organiza visualmente e verbalmente, observando que as escolhas dos componentes visuais e verbais se inter-relacionam/ complementam e devem ser consideradas na apreciação dos textos e nas suas produções, pois trazem um complexo de significação dentro de um contexto, 


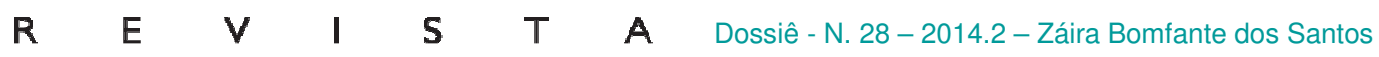

confirmando, assim, os pressupostos da Gramática Sistêmico-Funcional que privilegia as escolha que os indivíduos fazem ao usar a língua no contexto social em que estão inseridos: nesse escopo, mostrar ao leitor a necessidade/ importância de cuidar de si, se manter jovem, belo e saudável.

\section{Algumas considerações}

As contribuições da abordagem sistêmico-funcional em seus diversos estudos têm dado uma enorme contribuição para a compreensão de como a linguagem funciona em seus diversos contextos de uso, ressaltando, com isso, seu papel social. A compreensão dessa forte relação entre a linguagem e a esfera social, como vimos, passa necessariamente pela noção do que a linguagem é capaz de oferecer ao falante. Quando interpretamos a linguagem na perspectiva semântico-funcional proposta pela LSF, podemos, de alguma forma, lançar luz sobre uma questão problemática nos estudos linguísticos: como a linguagem constrói e é constrangida pelo contexto de comunicação?

Como vimos, enquanto teoria e metodologia, a LSF busca oferecer ao analista ferramentas descritivas que possibilitam a decomposição do texto em estruturas manejáveis de ordem discursiva e léxico-gramatical. Isso é possível porque a realização léxico-gramatical de nossas escolhas expõe a interface entre língua enquanto sistema e língua enquanto uso. A característica crucial da LSF, a saber, a linguagem como semiótica social, abre uma ampla perspectiva teórica e metodológica para se perceber a noção de texto além de critérios sintáticos formais, implicando uma visão de significados não como blocos de estruturas, mas como tensões e oposições que são construídas em uma ou mais maneiras.

\section{Referências bibliográficas:}

BAKHTIN, M. M. Os gêneros do discurso. In: Estética da Criação Verbal. São Paulo: Martins Fontes, 1997.

BRENT, G. Escolhas sistêmicas de transitividade e de léxico na representação de escândalos políticos: a construção de realidades de crise e de corrupção Dissertação de Mestrado, UFMG, 2011.

BÖHLKE. R. F. Constructing ideal body appearance for women: a multimodal analysis of a TV advertisement, 2008. Tese de Doutorado, UFSC. 
$\begin{array}{llllllll}\text { R } & \text { E } & \text { V } & \text { I } & \text { S } & \text { T } & \text { A } & \text { Dossiê - N. 28-2014.2-Záira Bomfante dos Santos }\end{array}$

EGGINS, S. An introduction to Systemic Functional Linguistics. 2.ed. London; New York: Continuum, 1994.

EGGINS, S.; MARTIN, J. Genres and Registers of Discourse. In: VAN DIJK, T. Discourse as Structure and Process. Vol. I. London; Thousand Oaks; New Delhi: Sage, 1997, p. 230256.

HALLIDAY, M. A. K. Explorations in the functions of language. London: Edward Arnold, 1973.

. Language as Social Semiotic: the social intepretation of language and meaning. Baltimore, MD: University Park Press, 1978.

An introduction to functional grammar. London: Edward Arnold, 1985.

An introduction to Functional Grammar. 2. ed. London: Edward Arnold, 1994.

; HASAN, R. Language, context and text: aspects of language in a social-semiotic perspective. Oxford: Oxford University Press, 1985.

; MARTIN, J. R. Writing science: literacy and discursive power. Pittsburgh: University of Pittsburgh Press, 1993.

; MATTHIESSEN, C. M. I. M. An introduction to Functional Grammar. $3^{\text {rd }}$ edition, London: Hodder Arnold, 2004.

HEBERLE, V. M. Análise crítica do discurso e estudos de gênero: subsídios para a leitura e interpretação de textos. In M. Fortkamp, L. Tomitch (Eds.). Aspectos da Lingüística Aplicada: estudos em homenagem ao Professor Hilário Inácio Bohn. Florianópolis, Insular, 2000, p. 289-316.

MARTIN, J. M.; ROSE, D. Working with Discourse: meaning beyond the clause. London; New York: Continuum, 2003.

MARTIN, J. M.; WHITE, P. The language of evaluation: appraisal in English. New York: Palgrave, 2005.

MEURER, J. L. Ampliando a noção de contexto na lingüística sistêmico- funcional e na análise crítica do discurso. Linguagem em (Dis)curso - LemD, Tubarão, v. 4, n. esp, p. 133157, 2004.

NEVES, M. H. M. Texto e gramática. 3. ed. São Paulo: Contexto, 2011.

A gramática funcional. São Paulo: Martins Fontes, 2005.

SAUSSURE, F. Curso de lingüística geral. São Paulo: Cultrix, 2001.

THOMPSON, G. Introducing Functional Grammar. 2. ed. Oxford: Oxford University Press, 2003. 


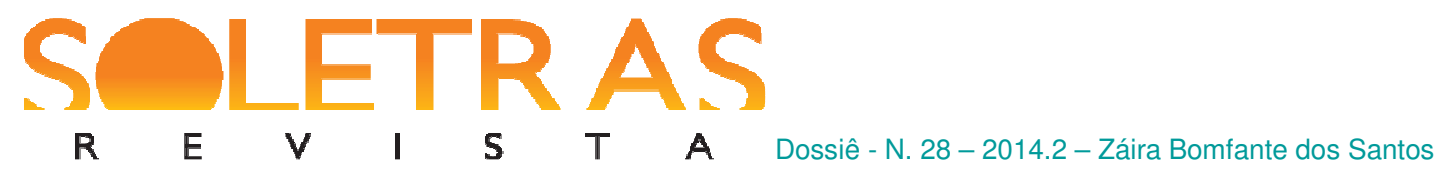

SANTOS, Z. B. Aspectos semióticos e lexicogramaticais de peças publicitárias. A construção de uma leitura multimodal. Dissertação de Mestrado, UFMG, 2009.

\title{
Sytemic Functional Linguistics: a brief overview
}

\begin{abstract}
This work aims to provide a brief overview of Systemic Functional Linguistics based on conceptions of Halliday (1994) and Halliday and Matthiessen (2004) by characterizing the theory from a social perspective and putting aside the formalism paradigms. Halliday and Matthiessen (2004) study the language as a social activity - proposing an approach in focusing attention on the users and uses of language. In this way, the Systemic Functional Grammar (GSF) is proposed, placing the language in its social context, exceeding the limit of the sentence and progressing to text analysis. Through considerations of some key concepts of the theory, we tried to explain how language functions in communicative contexts. We highlight, based on the functionalist approach, the notion of grammar and language system, language in social interaction, the realization of meanings as well as the notion of metafunction underpinning to the meanings carried out by language through text and context interrelationship. The purpose of this paper, with this brief introduction of systemic-functional approach, is to show how this theory provides useful tools for analyzing any instance of linguistic interaction in a context of communication, identifying linguistic and syntactic elements that are functional for the use of language. Thus, we bring some instances of national surveys that have drawn up this theoretical perspective.
\end{abstract}

Key words: Language. Grammar. Functions of language. Text and context. Sytemic Functional Linguistics.

Recebido em: 23 de setembro de 2014 .

Aprovado em: 13 de janeiro de 2015. 